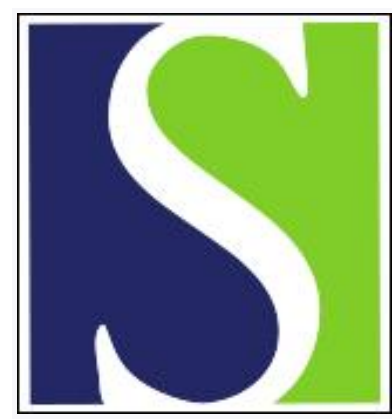

Scand J Work Environ Health 2004;30(6):468-476

https://doi.org/10.5271/sjweh.836

Issue date: Dec 2004

Sickness absence and the organization of nursing care among hospital nurses

by Kivimäki M, Mäkinen A, Elovainio M, Vahtera J, Virtanen M, Firth-Cozens J

Affiliation: Finnish Institute of Occupational Health, Department of Psychology, Topeliuksenkatu 41 a A, FI-00250 Helsinki, Finland. mika.kivimaki@ttl.fi

Refers to the following text of the Journal: 2003;29(1):1-4

Key terms: cohort study; hospital nurse; longitudinal study; managed care; nursing; nursing care; occupational health; organization of nursing care; sickness absence

This article in PubMed: www.ncbi.nlm.nih.gov/pubmed/15633598 


\title{
Sickness absence and the organization of nursing care among hospital nurses
}

\author{
by Mika Kivimäki, PhD, ${ }^{1,2}$ Arja Mäkinen, PhLic, ${ }^{1}$ Marko Elovainio, PhD, ${ }^{3}$ Jussi Vahtera, PhD, MD, ${ }^{3}$ Mari- \\ anna Virtanen, PhD, 2, 4 Jenny Firth-Cozens, $P h D^{5}$
}

Kivimäki M, Mäkinen A, Elovainio M, Vahtera J, Virtanen M, Firth-Cozens J. Sickness absence and the organization of nursing care among hospital nurses. Scand J Work Environ Health 2004;30(6):468-476.

\begin{abstract}
Objectives Primary nursing and team nursing are two different ways of organizing nurses' work in hospital wards. This study examined whether primary nursing is associated with lower sickness absence rates than team nursing is.

Methods Altogether 1213 nurses from 13 primary nursing wards and 13 team nursing wards participated in a 3year observational study. The nurses' sickness absence records were linked with information on the organization of nursing in the wards.

Results After adjustment for demographic and ward characteristics, primary nursing, compared with team nursing, was associated with 26-42\% higher annual rates of short (1-3 days) spells of sickness absence $(\mathrm{P}<0.05)$. The corresponding adjusted excess rates varied between $26 \%$ and $36 \%$ for the long $(>3$ days) absences, depending on the year $(\mathrm{P}<0.05)$. Among the primary and team nurses who had no sickness absence in the first year, primary nursing was associated with a $41 \%$ higher incidence of short-term sickness absence in the second year and a 56\% higher incidence in the third year.

Conclusions The expected benefits of primary nursing for nurses' health are not supported by data on recorded sickness absences. Recommendations to implement primary nursing in team nursing wards cannot be justified simply on the basis of potentially favorable effects on employee health.
\end{abstract}

Key terms study, cohort; study, longitudinal; managed care; nursing; health, occupational.

In hospital settings, there are several different ways of organizing nurses' work. They include primary nursing, team nursing, and functional nursing (1). Studies suggest that primary nursing, compared with other types of nursing, may result in a higher quality of nursing care (2) and greater patient satisfaction (3). However, it is not known whether primary nursing also provides a health advantage for nurses. Recorded sickness absence has been shown to be a strong correlate of morbidity and a powerful predictor of mortality, implying that such data could be used as a global measure of health differentials between employees (4-6).

The primary (or modullary) nursing mode refers to a work division in which patients are assigned to specific nurses. Thus primary nurses are responsible for the care of a small caseload of patients from admission to discharge from the ward; they take nursing notes and are assumed to collaborate with all other parties that participate in the care of their patients (1). In modified primary nursing, the unit is organized around relatively small geographic groupings of patients, called modules. Nursing personnel are permanently assigned to a module and are responsible for total care being distributed within the group. (7) In team nursing, nurses are assigned to separate nursing teams, which plan the nursing for the span of duty. Team leaders co-ordinate the care provided by their team, and, with the charge nurse, they share the responsibility for patient care and communication with other health care professionals and hospital departments (1). Functional or task-oriented nursing is a

1 University of Helsinki and the Finnish Institute of Occupational Health, Helsinki, Finland.

2 Finnish Institute of Occupational Health, Helsinki, and the Hospital District of Satakunta, Pori, Finland.

3 National Research and Development Centre for Welfare and Health, Helsinki, Finland.

4 The Invalid Foundation, Rehabilitation Unit of the Orthopaedic Hospital Orton, Helsinki, Finland.

5 University of Northumbria, Newcastle, United Kingdom.

Reprint requests to: Professor M Kivimäki, Finnish Institute of Occupational Health, Department of Psychology, Topeliuksenkatu 41 a A, FI-00250 Helsinki, Finland. [E-mail: mika.kivimaki@ttl.fi] 
mechanistic approach in which work is divided into separate tasks, which are assigned to each nurse by the nurse in charge, usually the charge nurse, who also retains the responsibility and accountability for the totality of the patient care (1). Although nurses do not always work according to these three theoretical models in every respect, the most dominant model is usually possible to identify in every ward (7).

The assumption that primary nursing may provide a healthier work environment for nurses derives from Karasek \& Theorell's demand-control-support model (8), which suggests that greater skill discretion and decision latitude at work are associated with a lower likelihood of health problems and sickness absence, a proposition supported by numerous prospective studies (913). Primary nursing may lead to greater skill discretion by expanding nurses' roles and offering challenges to develop practice, with associated decision latitude and autonomy. In a quasi-experimental study by Melchior et al (14), measurements of job characteristics were performed before and after the implementation of primary nursing in the intervention group and in the control group, which received no intervention. The intervention was found to be associated with an increase in autonomy (a concept close to skill discretion and decision latitude). This finding is in agreement with the results of several other studies reporting higher autonomy in primary nursing as compared with team and functional nursing (15-17).

However, studies of the association between nursing models and sickness absence are lacking, and empirical evidence on potential gains in health among primary nurses is mixed and limited to research on job satisfaction and stress. While some studies have found that primary nurses report significantly greater job satisfaction than those in team systems (18-21), other studies have not supported this association (22-24). Melchior et al (14) found a decrease in stress levels after primary nursing intervention, but at least two other intervention studies have obtained very different findings $(25,26)$.

In a study by Gardner (25), all the units had a comparable staffing and patient mix and used a functional nursing mode or a team nursing mode before the intervention. The intervention included the implementation of team and primary nursing, and postintervention data were collected 12 and 30 months after the implementation. Before the intervention the team nursing units had higher stress scores, but, after primary nursing was implemented, their stress scores were reduced and were similar to those of the workers in other units. Thus the highest stress experienced by nurses occurred when staff was anticipating the adoption of primary nursing.

Webb \& Pontin (26) also studied nurses' perceptions of the introduction of primary nursing. The data comprised qualitative interviews with nurses and responses to the nurse stress index at the beginning of the project and again 1 year later. Stress from managing the workload and dealing with patients and relatives increased over time, and nurses felt that they were working under greater pressure by the time of the second measurement.

These mixed findings raised the possibility that primary nursing may not necessarily be health protective. Expanded work roles among primary nurses may sometimes be a source of stress and a feeling of lower team support (ie, factors assumed to increase rather than decrease the risk of health problems) (9-13).

There are limitations in earlier research on nursing models, health, and well-being. First, nursing practices have often been determined by asking head nurses, charge nurses, or other nurses to provide a single label for their practice model. However, people may inconsistently use labels such as primary nursing and team nursing. Assessment at the more elementary level of individual aspects of work organization may therefore provide a more reliable basis for a researcher to determine which nursing models are used in the target wards (27). Such aspects include, for example, the grouping of nurses and length of allocation to specific patients, the allocation of nursing work, the organization of the duty rota, and nursing accountability for patient care (27).

Second, only few studies have reported or taken into account the time needed to implement a new way of working. Full adoption of an organizational model may take several years, during which well-being among the staff may be affected by stress from the change itself $(1,28,29)$. Therefore, it is important to complement existing evidence with longitudinal studies on stabilized nursing models. Controlling for selective attrition and confirming the temporal order between nursing mode and health have been suggested as essential for such research. (30)

Third, most of the study samples have been small, being comprised of fewer than 100 nurses and 10 wards, and few studies have included more than 300 nurses and 25 wards $(17,22,24)$. Larger sample sizes in studies could increase the strength of the evidence.

To exclude many of the limitations of prior research, we studied the association between nursing models and sickness absence in a large sample of nurses working in wards with stabilized nursing models. We used 3-year follow-up data on sickness absence records and determined the nursing model on the basis of reports of six individual aspects of work organization. We also studied the possibility of selective attrition to determine whether it could bias observed associations between nursing models and sickness absence. A subgroup analysis of nurses with no absence at entry into the study and a full follow-up was used to examine whether the difference in the nursing models preceded a change in sickness absence. 


\section{Study population and methods}

\section{Target wards and participants}

All 34 medical and surgical wards in which a three-shift system was used within two central hospitals and seven regional hospitals in Finland were included in this cohort study. We identified the organization of nursing in the wards by sending a standard self-report postal survey to charge nurses in the beginning of 1998 . The questionnaire on nursing models, developed by Thomas \& Bond (27), included six multichoice questions on the following features: (i) grouping of nurses and length of allocation to specific patients, (ii) allocation of nursing work, (iii) organization of the duty rota, (iv) nursing accountability for patient care, (v) responsibility for writing patients' nursing notes, and (vi) liaison with medical or paramedical staff $(24,28)$. (See the appendix.) The internal consistency of the questionnaire was high, as indicated by a Cronbach's alpha of $r=0.87$. The organization of nursing was determined according to the mean score for each of the six questions.

The questionnaire on nursing model was not received from four wards (response rate $88 \%$ ). In three other wards the organization of nursing care had been changed or the ward had been merged, split into parts, or had otherwise undergone a major restructuring during 1996-1998. In one ward, nursing care was organized according to the functional model. All of these wards were excluded from the study.

The final sample comprised 26 wards, of which 13 worked according to the primary nursing model (range of mean scores in the questionnaire 2.8-3.3) and 13 functioned according to the team nursing model (range 1.7-2.2). No changes in the nursing model had occurred during the study period in these wards (the information from the charge nurses and head nurses was consistent on this issue). According to the employers' records, a total of 1213 nurses (37 men and 1176 women) had a job contract in the target wards between 1996 and 1998. Of them, 629 had worked in primary nursing wards and 613 in team nursing wards ( 29 nurses changed between primary nursing and team nursing wards during the follow-up; 4 of them changed twice). Table 1 shows the demographic characteristics and organizational background of the primary and team nurses in each year of the follow-up.

The participants were representative of the eligible population (nurses in all 34 wards) from which they did not differ in terms of age (38.3 and 38.5 years), proportion of female employees ( $97 \%$ in both groups), proportion of permanent employees (51\% and 52\%), proportion of employees working in central hospitals ( $46 \%$ and $48 \%$ ), and numbers of short-term sick leaves (139.0 and 141.7 leaves/100 person-years) and long-term sick leaves (60.6 leaves/100 person-years in both groups).

\section{Sickness absences}

Data on sick leaves were collected from electronic records kept by the hospitals. The procedures for recording sick leave in Finnish public hospitals are reliable (6). Each sick-leave period taken by every employee is recorded, including the dates when each leave started and ended. In accordance with regulations, each sick-leave certificate, irrespective of its place of issue, must be forwarded for recording. For periods of absence of up to 3 days (short leaves), employees are able to complete their own certificates. For absences of more than 3 days (long leaves), medical certificates are required.

In Finland, hospital employees are paid a full salary during a sick leave. Absences due to care for a sick child are not recorded as sick leave. Regulations governing employment contracts in the public sector allow an employee to be absent from work for up to 3 days without

Table 1. Characteristics of the nurses by the type of work organization during a 3-year follow-up (total $\mathrm{N}=1213$ ).

\begin{tabular}{|c|c|c|c|c|c|c|c|}
\hline $\begin{array}{l}\text { Type of nursing } \\
\text { model }\end{array}$ & $\begin{array}{c}\text { Number } \\
\text { of } \\
\text { employees }\end{array}$ & $\begin{array}{c}\text { Mean } \\
\text { follow-up } \\
\text { period } \\
\text { (days/year) }\end{array}$ & $\begin{array}{l}\text { Mean } \\
\text { age } \\
\text { (years) }\end{array}$ & $\begin{array}{c}\text { Female } \\
\text { employees } \\
(\%)\end{array}$ & $\begin{array}{c}\text { Permanent } \\
\text { staff } \\
(\%)\end{array}$ & $\begin{array}{l}\text { Employees } \\
\text { working in } \\
\text { internal medi- } \\
\text { cine wards (\%) }\end{array}$ & $\begin{array}{l}\text { Employees } \\
\text { working in } \\
\text { central hos- } \\
\text { pitals (\%) }\end{array}$ \\
\hline \multicolumn{8}{|l|}{ Team nursing } \\
\hline Year 1 & 417 & 231 & 39.1 & 97.4 & 56.8 & 67.4 & 19.9 \\
\hline Year 2 & 464 & 226 & 38.5 & 97.6 & 51.7 & 72.0 & 21.1 \\
\hline Year 3 & 422 & 239 & 39.6 & 98.1 & 53.6 & 71.8 & 19.9 \\
\hline \multicolumn{8}{|l|}{ Primary nursing } \\
\hline Year 1 & 393 & 224 & 37.0 & 97.5 & 51.9 & 48.6 & 72.0 \\
\hline Year 2 & 413 & 228 & 37.0 & 98.3 & 51.1 & 44.8 & 70.4 \\
\hline Year 3 & 409 & 230 & 37.0 & 97.8 & 48.7 & 45.2 & 72.4 \\
\hline \multicolumn{8}{|l|}{$P$ for difference } \\
\hline Year 1 & & 0.394 & 0.002 & 0.934 & 0.159 & $<0.001$ & $<0.001$ \\
\hline Year 2 & & 0.786 & 0.017 & 0.482 & 0.851 & $<0.001$ & $<0.001$ \\
\hline Year 3 & & 0.304 & $<0.001$ & 0.757 & 0.158 & $<0.001$ & $<0.001$ \\
\hline
\end{tabular}


loss of salary to care for a child under 10 years of age with an acute illness. There are no limitations on the number of such 3-day leaves per employee per year. Thus the participants had no reason to falsely report being ill when staying at home to care for a sick child.

We grouped all short and long periods of sickness absence that occurred from 1 January to 31 December for the years 1996, 1997, and 1998 (referred to as years 1 to 3 , respectively). We checked records for inconsistencies and combined any overlapping or consecutive periods of sickness absence.

\section{Analyses}

Differences in the measures of the demographic characteristics and organizational background between the primary and team nurses were detected by the chi-square test for categorical variables (gender, occupation, speciality, and hospital context) and by an analysis of variance for continuous variables (mean follow-up time and age). For each person the numbers of short and long sick leaves were computed, and the follow-up period was measured in person-years. The rates and mean durations of the sick leaves were computed. Changes in sickness absence and person-years during the 3-year study period were tested by a repeated-measures analysis of variance. The differences in the annual mean duration of the short and long sick leaves between the team and primary nurses were tested with an analysis of variance.

The sick-leave rate is not normally distributed. Instead, it takes the discrete nonnegative values $0,1,2$, and so forth, and demonstrates a strongly skewed distribution, low values being the most frequent and high values being rarely observed (ie, a Poisson distribution). Traditional regression models, which are based on a normal distribution, may lead to serious problems in modeling a dependent variable following a Poisson distribution (31). For this reason, Poisson regression models, being specifically developed for use with such response variables, were applied $(9,11,12,32,33)$. We determined the rates of short and long sick leaves for the primary and team nurses and calculated the corresponding rate ratios and their $95 \%$ confidence intervals using a Poisson regression analysis. The rate ratios refer to the ratios of the absence rates at different levels of predictors. We adjusted the rate ratios for age (a continuous variable), speciality (medical ward versus surgical ward), and place of work (central hospital versus regional hospital). With respect to these variables, the primary and team nurses differed from each other (table 1).

We focused on subgroups to study the potential attrition bias and temporal order between variables (30). First, the logistic regression analysis was used to determine whether the organization of nursing and the characteristics of the participants were predictive of turnover (versus staying in the cohort). Second, we compared the absence rates using a Poisson regression analysis between the primary and team nurses who stayed in the cohort and had no sickness absence in the first year of follow-up. In this subgroup, the difference in the organization of nursing precedes changes in absence levels.

\section{Results}

For the total sample, the mean rates of short and long sick leave were 1.39 and 0.61 leaves/person-year, respectively. There were no significant changes in the rate of short sick leaves $[\mathrm{F}(2,2424)=0.07, \mathrm{P}=0.936]$ or long sick leaves $[\mathrm{F}(2,2424)=0.71, \mathrm{P}=0.492]$ during the follow-up, but the total number of days that employees had a work contract (ie, contracted days) increased 5-8\% after the first year of follow-up $[\mathrm{F}(2,2424)=5.45$, $\mathrm{P}=0.004]$.

Among the primary nurses, the mean duration of the short sick leaves varied between 1.81 to 1.86 days/leave, depending on the year of follow-up. Among the team nurses, the corresponding range was 1.74-1.80 days/ leave. The mean duration of the short leaves did not differ between the primary and team nurses in any of the years of follow-up (P-values for difference between 0.086 and 0.528 ).

The mean duration of the long sick leaves varied between 16.2 and 18.5 days/leave among the primary nurses and between 16.4 and 21.2 days/leave among the team nurses. Again, there were no significant differences in the durations between the team and primary nurses (P-values between 0.139 and 0.869).

Table 2 shows that the rates for short sick leaves were 1.2 to 1.4 times higher among the primary nurses than among the team nurses irrespective of adjustments.

Table 2. Rate ratios (RR) for short-term sick leave and their $95 \%$ confidence intervals $(95 \% \mathrm{Cl})$ for primary versus team nursing by the year of follow-up.

\begin{tabular}{|c|c|c|c|c|c|c|}
\hline \multirow{2}{*}{$\begin{array}{l}\text { Year of } \\
\text { follow-up }\end{array}$} & \multirow{2}{*}{$\begin{array}{l}\text { Person- } \\
\text { years }\end{array}$} & \multirow{2}{*}{$\begin{array}{l}\text { Absence } \\
\text { rate / } \\
\text { person- } \\
\text { year }\end{array}$} & \multicolumn{2}{|c|}{ Unadjusted } & \multicolumn{2}{|c|}{ Adjusted a } \\
\hline & & & $\mathrm{RR}$ & $95 \% \mathrm{Cl}$ & $\mathrm{RR}$ & $95 \% \mathrm{Cl}$ \\
\hline \multicolumn{7}{|l|}{ Year 1 (1996) } \\
\hline Team nursing & 263.9 & 1.21 & 1.00 & .. & 1.00 & .. \\
\hline Primary nursing & 240.8 & 1.69 & 1.39 & $1.20-1.61$ & 1.42 & $1.22-1.66$ \\
\hline \multicolumn{7}{|l|}{ Year 2 (1997) } \\
\hline Team nursing & 286.7 & 1.25 & 1.00 & .. & 1.00 & .. \\
\hline Primary nursing & 257.8 & 1.49 & 1.19 & $1.03-1.38$ & 1.26 & $1.08-1.47$ \\
\hline \multicolumn{7}{|l|}{ Year 3 (1998) } \\
\hline Team nursing & 276.2 & 1.17 & 1.00 & .. & 1.00 & .. \\
\hline Primary nursing & 258.3 & 1.59 & 1.35 & $1.17-1.57$ & 1.37 & $1.17-1.60$ \\
\hline
\end{tabular}

a Adjusted for age, speciality, and hospital type. 
All these rate ratios were statistically significant. The corresponding rate ratios for long sick leaves were 1.2 to 1.4 , respectively (table 3 ).

Table 4 presents the results for the factors predicting turnover during the follow-up. Of the 810 employees who worked in the first year of follow-up, 509 were still working at the end of the follow-up period, and 301

Table 3. Rate ratios (RR) for long-term sick leave and their 95\% confidence intervals $(95 \% \mathrm{Cl})$ for primary versus team nursing by the year of follow-up.

\begin{tabular}{|c|c|c|c|c|c|c|}
\hline \multirow{2}{*}{$\begin{array}{l}\text { Year of } \\
\text { follow-up }\end{array}$} & \multirow{2}{*}{$\begin{array}{l}\text { Person- } \\
\text { years }\end{array}$} & \multirow{2}{*}{$\begin{array}{c}\text { Absence } \\
\text { rate / } \\
\text { person- } \\
\text { year }\end{array}$} & \multicolumn{2}{|c|}{ Unadjusted } & \multicolumn{2}{|c|}{ Adjusted a } \\
\hline & & & $\mathrm{RR}$ & $95 \% \mathrm{Cl}$ & $\mathrm{RR}$ & $95 \% \mathrm{Cl}$ \\
\hline \multicolumn{7}{|l|}{ Year 1 (1996) } \\
\hline Team nursing & 263.9 & 0.55 & 1.00 & .. & 1.00 & .. \\
\hline Primary nursing & 240.8 & 0.66 & 1.20 & $0.96-1.51$ & 1.29 & $1.02-1.64$ \\
\hline \multicolumn{7}{|l|}{ Year 2 (1997) } \\
\hline Team nursing & 286.7 & 0.50 & 1.00 & .. & 1.00 & .. \\
\hline Primary nursing & 257.8 & 0.69 & 1.40 & $1.13-1.75$ & 1.36 & $1.08-1.73$ \\
\hline \multicolumn{7}{|l|}{ Year 3 (1998) } \\
\hline Team nursing & 276.2 & 0.56 & 1.00 & .. & 1.00 & .. \\
\hline Primary nursing & 258.3 & 0.70 & 1.26 & $1.01-1.56$ & 1.26 & $1.00-1.59$ \\
\hline
\end{tabular}

${ }^{a}$ Adjusted for age, speciality, and hospital type.

Table 4. Predictors of turnover. ${ }^{\mathrm{a}}(95 \% \mathrm{Cl}=95 \%$ confidence interval)

\begin{tabular}{|c|c|c|}
\hline Predictor & Odds ratio & $95 \% \mathrm{Cl}$ \\
\hline \multicolumn{3}{|l|}{ Type of nursing model } \\
\hline Team nursing & 1.00 & . \\
\hline Primary nursing & 1.85 & $1.39-2.47$ \\
\hline \multicolumn{3}{|l|}{ Age group } \\
\hline 20-29 years & 3.14 & $2.13-4.64$ \\
\hline $30-39$ years & 1.00 & \\
\hline $40-49$ years & 0.56 & $0.38-0.83$ \\
\hline $50-60$ years & 0.82 & $0.52-1.30$ \\
\hline \multicolumn{3}{|l|}{ Gender } \\
\hline Women & 1.00 & . \\
\hline Men & 2.83 & $1.16-6.90$ \\
\hline \multicolumn{3}{|l|}{ Job contract } \\
\hline Permanent & 1.00 & . \\
\hline Temporary or fixed term & 5.48 & $4.01-7.48$ \\
\hline \multicolumn{3}{|l|}{ Speciality } \\
\hline Internal medicine & 1.00 & . \\
\hline Surgery & 1.43 & $1.07-1.90$ \\
\hline \multicolumn{3}{|l|}{ Hospital type } \\
\hline Regional & 1.00 & . \\
\hline Central & 1.74 & $1.31-2.32$ \\
\hline \multicolumn{3}{|c|}{ Short-term sick leave (leaves of 1-3 days/person-year) } \\
\hline 0 days & 1.00 & . \\
\hline 1 days & 0.35 & $0.23-0.51$ \\
\hline$\geq 2$ days & 0.77 & $0.55-1.08$ \\
\hline \multicolumn{3}{|c|}{ Long-term sick leave (leaves of $>3$ days/person-year) } \\
\hline 0 days & 1.00 & . \\
\hline 1 days & 0.37 & $0.24-0.59$ \\
\hline$\geq 2$ days & 0.77 & $0.47-1.26$ \\
\hline
\end{tabular}

a Of the 810 employees who worked in the first year of follow-up, 509 still worked in the third year, and 301 had left or lost their job before the third year. had left or lost their job during the follow-up. The turnover was higher in the primary nursing wards than in the team nursing wards. Young male employees with a temporary or fixed-term job contract were also more likely to leave their jobs than other employees were. Other predictors of turnover included working in a surgical ward of a central hospital and no sickness absence at baseline. A higher turnover among the low-absence employees may lead to an overestimation of the sickness absence rate in primary nursing wards, compared with the rate of team nursing wards, only in the unlikely situation in which newly hired workers have a higher absence rate than those who leave.

To evaluate whether the association between the nursing models and sickness absence is attributable to differences in turnover rate, we studied the employees who worked for the entire 3-year follow-up period. Table 5 shows that the rate ratios for short sick leave between the primary and team nurses varied between 1.3 and 1.5 , being statistically significant at the probability level of $\mathrm{P}<0.001$. Adjustments for age, speciality, and hospital type did not alter these figures. To study sickness absence incidence, we further restricted our analyses to the primary and team nurses who had no sickness absence in the first year. The adjusted incidence of short sick leaves was 1.4 times higher for the primary nurses than for the team nurses in the second year and 1.6 times higher in the third year. This finding is consistent with

Table 5. Rate ratios (RR) for short-term sick leave and their $95 \%$ confidence intervals $(95 \% \mathrm{CI})$ for primary versus team nursing among all the employees who worked in 1996 (year 1), 1997 (year 2), and 1998 (year 3) ( $\mathrm{N=509)}$ and those who had no shortterm sick leaves in $1996(\mathrm{~N}=254)$.

\begin{tabular}{|c|c|c|c|c|c|c|}
\hline \multirow[t]{2}{*}{ Population } & \multirow{2}{*}{$\begin{array}{l}\text { Person- } \\
\text { years }\end{array}$} & \multirow{2}{*}{$\begin{array}{l}\text { Absence } \\
\text { rate / } \\
\text { person- } \\
\text { year }\end{array}$} & \multicolumn{2}{|c|}{ Unadjusted } & \multicolumn{2}{|c|}{ Adjusted a } \\
\hline & & & $\mathrm{RR}$ & $95 \% \mathrm{Cl}$ & $\mathrm{RR}$ & $95 \% \mathrm{Cl}$ \\
\hline \multicolumn{7}{|c|}{ Employees with a full follow-up period } \\
\hline \multicolumn{7}{|l|}{ Year 1 of follow-up } \\
\hline Team nursing & 219.4 & 1.12 & 1.00 & .. & 1.00 & .. \\
\hline Primary nursing & g 160.8 & 1.62 & 1.45 & $1.22-1.72$ & 1.46 & $1.19-1.79$ \\
\hline \multicolumn{7}{|c|}{ Year 2 of follow-up } \\
\hline Team nursing & 225.9 & 1.09 & 1.00 & $\cdot \cdot$ & 1.00 & .. \\
\hline Primary nursing & g 177.6 & 1.44 & 1.32 & $1.11-1.57$ & 1.32 & $1.08-1.63$ \\
\hline \multicolumn{7}{|c|}{ Year 3 of follow-up } \\
\hline & 21 & 1.1 & 1.00 & .. & 1.00 & .. \\
\hline Primary nursing & g 175.0 & 1.61 & 1.40 & $1.18-1.66$ & 1.44 & $1.18-1.75$ \\
\hline
\end{tabular}

Employees with a full follow-up period and no sickness absence in the first year

\begin{tabular}{|c|c|c|c|c|}
\hline \multicolumn{5}{|l|}{ Year 2 of follow-up } \\
\hline Team nursing & 121.2 & 0.73 & 1.00 & 1.00 \\
\hline Primary nursing & 71.9 & 1.06 & $1.441 .06-1.95$ & $1.41 \quad 1.01-1.97$ \\
\hline \multicolumn{5}{|l|}{ Year 3 of follow-up } \\
\hline Team nursing & 117.1 & 0.6 & 1.00 & 1.00 \\
\hline Primary nursing & 71.2 & 1.07 & $1.641 .20-2.26$ & $1.561 .11-2.20$ \\
\hline
\end{tabular}

a Adjusted for age, speciality, and hospital type. 
the possibility that the risk of absence increases with the time worked in primary nursing wards.

Among the employees who worked for the entire follow-up period, the adjusted rates for the long sick leaves were 1.2 to 1.6 times higher among the primary nurses than among the team nurses (table 6). There was no support for a dose-response relationship.

\section{Discussion}

This study suggests that primary nursing is not associated with lower sickness absence levels among hospital nurses. In fact, the primary nurses in our study took short-term sick leaves more frequently than did team nurses in each year of the follow-up. Although the possibility of confounding by an unknown factor can never be excluded in observational studies, a major bias remains unlikely in our investigation. The primary nursing wards did not differ from the team nursing wards in terms of the staff's gender distribution and use of temporary employees. The sample comprised only wards operating on a three-shift schedule; wards with major restructuring or changes in nursing practices were excluded from the study. During the study period, there was a slight increase in the staffing levels, as indicated by the $5-8 \%$ increase in contracted days, but no significant change occurred in the sickness absence figures. Differences in age, speciality mix, and hospital type between the nursing models were controlled statistically.

Prior studies of nursing models have relied on selfreports of health. To complement this body of research, we used recorded sickness absences. The quality of absence data in terms of coverage, accuracy, and consistency over time is likely to be higher than that attainable via self-reports. Since the process of recording sick leave is a routine procedure, the impact of measurement on the responses being obtained is minimized. Indeed, the rate of long sick leaves has been a more powerful predictor of mortality than established self-reported health measures have been (4-6).

In our study, primary nursing was not associated with lower rates of long (medically certified) sickness absences. Of the mixed evidence from prior research, our observations corresponded with those that did not support the hypothesized benefits of primary nursing on employee health (22-25). In addition, the nursing models did not significantly explain the variation in the perceived workload in a cohort partially overlapping our present one (34). Thus it seems unlikely that primary nursing would lead to substantial gains in terms of employee health or reduced long-term absenteeism.

In our study, primary nursing was consistently associated with greater rates of sickness absence than team
Table 6. Rate ratios (RR) for long-term sick leave and their 95\% confidence intervals $(95 \% \mathrm{Cl})$ for primary versus team nursing among all the employees who worked in 1996 (year 1), 1997 (year 2), and 1998 (year 3) (N=509) and those who had no longterm sick leave in $1996(\mathrm{~N}=353)$.

\begin{tabular}{|c|c|c|c|c|c|c|}
\hline \multirow[t]{2}{*}{ Population } & \multirow{2}{*}{$\begin{array}{l}\text { Person- } \\
\text { years }\end{array}$} & \multirow{2}{*}{$\begin{array}{c}\text { Absence } \\
\text { rate / } \\
\text { person- } \\
\text { year }\end{array}$} & \multicolumn{2}{|c|}{ Unadjusted } & \multicolumn{2}{|c|}{ Adjusted a } \\
\hline & & & $\mathrm{RR}$ & $95 \% \mathrm{Cl}$ & $\mathrm{RR}$ & $95 \% \mathrm{Cl}$ \\
\hline \multicolumn{7}{|c|}{ Employees with a full follow-up period } \\
\hline \multicolumn{7}{|l|}{ Year 1 of follow-up } \\
\hline Team nursing & 219.4 & 0.54 & 1.00 & .. & 1.00 & \\
\hline Primary nursing & g 160.8 & 0.66 & 1.22 & $0.94-1.59$ & 1.24 & $0.92-1.68$ \\
\hline \multicolumn{7}{|c|}{ Year 2 of follow-up } \\
\hline Team nursing & 225.9 & 0.47 & 1.00 & .. & 1.00 & \\
\hline Primary nursing & g 177.6 & 0.74 & 1.57 & $1.22-2.02$ & 1.65 & $1.22-2.23$ \\
\hline \multicolumn{7}{|l|}{ Year 3 of follow-up } \\
\hline Team nursing & 219.0 & 0.53 & 1.00 & .. & 1.00 & .. \\
\hline Primary nursing & 175.0 & 0.81 & 1.51 & $1.19-1.94$ & 1.52 & $1.14-2.03$ \\
\hline \multicolumn{7}{|c|}{$\begin{array}{l}\text { Employees with a full follow-up period and no sickness absence in the } \\
\text { first year }\end{array}$} \\
\hline \multicolumn{7}{|l|}{ Year 2 of follow-up } \\
\hline Team nursing & 159.1 & 0.34 & 1.00 & .. & 1.00 & 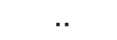 \\
\hline Primary nursing & 117.7 & 0.54 & 1.60 & $1.12-2.30$ & 1.34 & $0.90-1.99$ \\
\hline \multicolumn{7}{|l|}{ Year 3 of follow-up } \\
\hline Team nursing & 152.2 & 0.43 & 1.00 & .. & 1.00 & .. \\
\hline Primary nursing & 117.3 & 0.55 & 1.28 & $0.91-1.80$ & 1.23 & $0.85-1.77$ \\
\hline
\end{tabular}

a Adjusted for age, speciality, and hospital type.

nursing was. This difference was particularly true for short sick leaves, and it supports the hypothesis that primary nursing may, in fact, increase rather than decrease the risk of sickness absence. Additional research is needed to determine the underlying mechanisms. One possibility is that the expanded work roles of primary nurses, in practice, require a higher level of functioning (eg, lifting the patient without help) and thus increase stress and lower the threshold for sick leave. Primary nurses are accountable for comprehensive care, but, in team nursing, this accountability is shared and team support is more likely (35).

Selection bias and reversed causality are other potential explanations for the greater rate of short absences among primary nurses. In our study, the odds for turnover were 1.7 times greater for the primary nursing wards than for the team nursing wards. The employees who left the organization more often had no sickness absence than those who stayed. This finding raises the possibility that increased rates of sickness absence in primary nursing wards are attributable to the selection of healthy workers out of the sample (an attrition bias). However, the results of the nurses who worked the entire follow-up period and had no sickness absence in the first year do not support this interpretation. In this subcohort, the absence rate was greater among the primary nurses than among the team nurses in the second year of follow-up, and this difference grew in the third year. This temporal sequence, in which primary nursing was 
associated with poorer absence trends than team nursing was, is against attrition bias and reverse causation explanations. This result also makes it unlikely that the higher absence rate among the primary nurses was attributable to a higher absence rate among them already before the study started or that primary nursing would have been introduced as a curative measure against high sickness absence.

Future research is needed to specify the conditions in which primary nursing can increase sickness absence. In such studies, it would be important to examine the full sequence of variables from nursing mode to job characteristics (skill discretion and decision latitude in particular), health, and subsequent sickness absence across different economic and work contexts. Complementary indicators of work and health should be added to the measurement battery. In our present study, the determination of the nursing models was based on the charge nurses' reports. Additional questionnaire data from nurses could indicate how consistently these practices are actually applied across different shifts and staffing levels. An exploration of the diagnosed morbidity would provide information on whether excess sickness absence among primary nurses is disease specific. For example, musculoskeletal disorders and diseases related to poor immune function and cardiovascular problems are expected if primary nursing is associated with chronically elevated stress levels $(10,36)$.

In summary, this 3-year study of employers' records on job contracts and sickness absence in a large sample of nurses extends existing knowledge on the association between nursing models and health of employees. It avoided methodological drawbacks related to commonmethod bias and largely controlled for the operation of sample attrition and reverse causation. Our evidence suggests that primary nursing does not provide a curative measure against sickness absence among nurses.

\section{Acknowledgments}

This study was supported in part by the Finnish Work Environment Fund and the Academy of Finland (projects 77560, 104891 and 105195).

\section{References}

1. Marram G, Schlegel M, Bevis EO. Primary nursing: a model for individualized care. Saint Louis (MO): Mosby; 1979.

2. Felton G. Increasing the quality of nursing care by introducing the concept of primary nursing: a model project. Nurs Res 1975;24:27-32.

3. Ventura MR, Fox RN, Corley MC, Mercurio SM. A patient satisfaction measure as a criterion to evaluate primary nursing. Nurs Res 1982;31:226-30.

4. Marmot MG, Feeney A, Shipley M, North F, Syme SL. Sickness absence as a measure of health status and functioning: from the UK Whitehall II study. J Epidemiol Community Health 1995;49:124-30.

5. Kivimäki M, Head J, Ferrie JE, Shipley M, Vahtera J, Marmot MG. Sickness absence as a global measure of health: Evidence from mortality in the Whitehall II study. BMJ 2003; 327:364-69.

6. Vahtera J, Kivimäki M, Pentti J. Sickness absence as a predictor of mortality among male and female employees. J Epidemiol Community Health, 2004;58:321-26.

7. Tomey AM. Guide to nursing management and leadership. 6th ed. St Louis (MO): Mosby; 2000.

8. Karasek RA, Theorell T. Stress, productivity and reconstruction of working life. New York (NY): Basic Books; 1990.

9. North F, Syme SL, Feeney A, Shipley MJ, Marmot MG. Psychosocial work environment and sickness absence among British civil servants: the Whitehall II study. Am J Public Health 1996;86:332-40.

10. Hemingway H, Marmot MG. Psychosocial factors in the aetiology and prognosis of coronary heart disease: systemic review of prospective cohort studies. BMJ 1999;1460-7.

11. Vahtera J, Kivimäki M, Pentti J, Theorell T. Effect of change in the psychosocial work environment on sickness absence: a seven year follow up of initially healthy employees. J Epidemiol Community Health 2000;54:484-93.

12. Kivimäki M, Vahtera J, Pentti J, Ferrie JE. Factors underlying the effect of organisational downsizing on health of employees: longitudinal cohort study. BMJ 2000;320:971-5.

13. Melchior M, Niedhammer I, Berkman LF, Goldberg M. Do psychosocial work factors and social relations exert independent effects on sickness absence?: a six year prospective study of the GAZEL cohort. J Epidemiol Community Health 2003; 57:285-93.

14. Melchior ME, Halfens RJ, Abu-Saad HH, Philipsen H, van den Berg AA, Gassman P. The effects of primary nursing on work-related factors. J Adv Nurs 1999;29:88-96.

15. Thomas LH. Qualified nurse and nursing auxiliary perceptions of their work environment in primary, team and functional nursing wards. J Adv Nurs 1992;17:373-83.

16. Alock D, Lawrence J, Goodman J, Ellis J. Formative evaluation: implementation of primary nursing. Can J Nurs Res 1993;25:15-28.

17. Manley K, Hamill JM, Hanlon M. Nursing staff's perceptions and experiences of primary nursing practice in intensive care 4 years on. J Clin Nurs 1997;6:277-87.

18. Carlsen RH, Malley JD. Job satisfaction of staff registered nurses in primary and team nursing delivery systems. Res Nurs Health 1981;4:251-60.

19. Sellick KJ, Russell S, Beckmann JL. Primary nursing: an evaluation of its effects on patient perception of care and staff satisfaction. Int J Nurs Stud 1983;20:265-73.

20. Song R, Daly BJ, Rudy EB, Douglas S, Dyer MA. Nurses' job satisfaction, absenteeism, and turnover after implementing a special care unit practice model. Res Nurs Health 1997; 20:443-52.

21. Reed SE. A comparison of nurse-related behaviour, philosophy of care and job satisfaction in team and primary nursing. $\mathrm{J}$ Adv Nurs 1988;13:383-95.

22. Alexander CS, Weisman CS, Chase GA. Evaluating primary nursing in hospitals: examinations of effects on nursing staff. Med Care 1981;19:80-9. 
23. Wilson NW, Dawson P. A comparison of primary nursing and team nursing in a geriatric long-term care setting. Int J Nurs Stud 1989;26:1-13.

24. Mäkinen A, Kivimäki M, Elovainio M, Virtanen M, Bond S. Organization of nursing care as a determinant of job satisfaction among hospital nurses. J Nurs Manage 2003;11:299-306.

25. Gardner K. A summary of findings of a five-year comparison study of primary and team nursing. Nurs Res 1991;40:113-7.

26. Webb C, Pontin D. Introducing primary nursing: nurses' opinion. J Clin Nurs 1996;5:351-58.

27. Thomas LH, Bond S. Towards defining the organization of nursing care in hospital wards: an empirical study. J Adv Nurs 1990;15:1106-12.

28. Kompier MAJ, Geurts SAE, Gruendemann RWM, Vink P, Smulders PG. The success of a participative and stepwise approach. Stress Med 1998; 14:155-68.

29. Lindström K, Kivimäki M. Organizational interventions and employee well-being in health care settings. In: Le Blanc PM, Peters MCW, Bussing A, Shaufeli WB, editors. Organizational psychology and health care: European contributions. Munich (Germany): Hampp; 1999. p 135-51.

30. Taris TW, Kompier M. Challenges in longitudinal designs in occupational health psychology [editorial]. Scand J Work Environ Health 2003;29(1):1-4.

31. McCullagh P, Nelder JA. Generalized linear models. London: Chapman \& Hall; 1989.

32. Vahtera J, Kivimäki M, Pentti J. Effect of organisational downsizing on health of employees. Lancet 1997;350:1124-8.

33. Kivimäki M, Sutinen R, Elovainio M, Vahtera J, Räsänen K, Töyry S, et al. Sickness absence in hospital physicians: 2-year follow up on determinants. Occup Environ Med 2001;58:3616.

34. Mäkinen A, Kivimäki M, Elovainio M, Virtanen M. Organization of nursing care and stressful work characteristics. J Adv Nurs 2003;43:197-205.

35. Carter AJ, West MA. Sharing the burden-team work in health care setting. In: Firth-Cozens J, Payne R, editors. Stress in health professionals: psychological and organizational causes and interventions. Chichester (UK): Wiley; 1999. p $323-$ 61.

36. McEwen BS. Protective and damaging effects of stress mediators. N Engl J Med 1998;338:171-79.

Received for publication: 1 November 2001 


\section{Appendix}

\section{Questionnaire filled out by the charge nurses}

\section{Scoring: 1 = task allocation or functional nursing, 2 = team nursing, 3 and $4=$ primary nursing}

1. Please read through the following list and tick which one most accurately describes the way you organize staff on your ward.

A. The ward staff is organized as one group and is allocated singly, in pairs, or in threes to patients or ward areas for part of their shift, and it works across the whole ward for the remainder. (Score 1)

B. The ward staff is organized as one group and is allocated singly, in pairs, or in threes to patients or ward areas for their entire shift. (Score 1)

C. The ward staff is divided into teams with a designated leader and is allocated to a group of patients for one shift or part of a shift. (Score 2)

D. The ward staff is divided into teams with a designated leader and is allocated to a group of patients for periods longer than one shift. (Score 2)

E. Individual qualified nurses are given the responsibility for individual patients for the duration of a shift or part of a shift. (Score 3)

F. Individual qualified nurses are given the responsibility for individual patients for periods longer than one shift, but less than the total duration of the patient's stay in the hospital. (Score 3)

G. Individual qualified nurses are given the responsibility for individual patients for the duration of the patient's stay in the hospital. (Score 4)

If none of the above applies, please describe below your method of organizing staff. (Score 1-4, one of the authors, AM, a registered nurse, scored the responses)

2. Under usual staffing conditions, who allocates work when nurses come on duty?
A. The charge nurse or nurse in charge allocates work. (Score 1)
B. Team leaders allocate work for their team. (Score 2)
C. The most senior nurse in the team allocates work. (Score 2)
D. Individual nurses decide what care to give their individual patients. (Score 4)

If none of the above applies, please describe below the method used in your ward. (Score 1-4, a registered nurse, AM, scored the responses)
3. Is the off-duty time (or duty rota) organized:

A. For the ward as a whole? (Score 1)

B. Within two or more groups or teams? (Score 2)

C. To enable individual nurses to be responsible for individual patients? (Score 4)

If none of the above applies, please describe below your method of organizing staff. (Score 1-4, one of the authors, AM, a registered nurse, scored the responses)

4. Who has nursing accountability for patients?

A. It is entirely vested by the charge nurse. (Score 1)

B. It is entirely vested by the team leader. (Score 2)

C. It is shared. (Score 1-4)

D: It is entirely vested by the individual nurse responsible for individual patients. (Score 4)

If $\mathrm{C}$ applies, please indicate how accountability is shared. (Score 1-4, one of the authors, AM, a registered nurse, scored the responses)

5. Who is responsible for writing the nursing notes?

A. The charge nurse or nurse in charge writes the notes for most of the patients. (Score 1)

B: Each team leader writes the notes for patients in his or her team. (Score 2)

$\mathrm{C}$ : Individual nurses write the notes for their individual patients. (Score 4)

D. The nurse who has provided care for the patient during the shift does so. (Score 3)

If none of the above applies, please describe below the method used in your ward. (Score 1-4, one of the authors, AM, a registered nurse, scored the responses)

6. Who liaises with the medical staff about patient care?

A. The charge nurse or nurse in charge. (Score 1)

B. The team leader, when it involves her patients. (Score 2)

C. Any qualified nurse available. (Score 3)

D. The patient's individual nurse. (Score 4)

If none of the above applies, please describe below the method used in your ward. (Score 1-4, one of the authors, AM, a registered nurse, scored the responses) 